Quim. Nova, Vol. 36, No. 5, 720-724, 2013

\title{
DETERMINAÇÃO SIMULTÂNEA DE TOPIRAMATO, CARBAMAZEPINA, FENITOÍNA E FENOBARBITAL EM PLASMA EMPREGANDO CROMATOGRAFIA A GÁS COM DETECTOR DE NITROGÊNIO E FÓSFORO
}

\author{
Roberta Zilles Hahn, Olyr Celestino Kreutz, Marina Venzon Antunes e Rafael Linden* \\ Instituto de Ciências da Saúde, Universidade Feevale, Rod.RS 239, 2755, 93352-000 Novo Hamburgo - RS, Brasil \\ Juliana da Silva e Cléber Álvares da Silva \\ Irmandade Santa Casa de Misericórdia de Porto Alegre, Rua Prof. Annes Dias, 295, 90020-090 Porto Alegre - RS, Brasil
}

Recebido em 21/7/12; aceito em 22/11/12; publicado na web em 6/3/13

\begin{abstract}
SIMULTANEOUS DETERMINATION OF TOPIRAMATE, CARBAMAZEPINE, PHENYTOIN AND PHENOBARBITAL IN PLASMA BY GAS CHROMATOGRAPHY WITH NITROGEN PHOSPHORUS DETECTOR. Topiramate and the other frequently co-administered antiepileptic drugs carbamazepine, phenytoin and phenobarbital were determined in $100 \mu \mathrm{L}$ plasma samples by gas chromatography with nitrogen phosphorus detection (GC-NPD), after a one-step liquid-liquid extraction with ethyl acetate, followed by flash methylation with trimethylphenylammonium hydroxide. Total chromatographic run time was 12.5 min. Intra-assay and inter-assay precision was $2.5-7.3 \%$ and $1.6-5.2 \%$, respectively. Accuracy was $100.1-104.2 \%$. The limit of quantitation was $1 \mu \mathrm{g} \mathrm{mL} L^{-1}$ for all analytes, proving suitable for routine application in therapeutic drug monitoring of antiepileptic drugs.
\end{abstract}

Keywords: topiramate; gas chromatography nitrogen phosphorus detector; TMAH.

\section{INTRODUÇÃO}

O topiramato (2,3:4,5-bis- $O$-(-1-metiletiledeno)- $\beta$-D-frutopiranosesulfamato) é um derivado sulfamato de um monossacarídeo de ocorrência natural, sendo utilizado como tratamento adjuvante de crises convulsivas parciais, com ou sem generalização secundária, em adultos e crianças. ${ }^{1,2}$ Também é usado para o tratamento da Síndrome Lennox-Gastaut para crises primárias tônico-clônicas generalizadas em pacientes inadequadamente controlados por outros antiepilépticos. ${ }^{1,2} \mathrm{O}$ topiramato (TPM) age bloqueando os canais de sódio e potencializando a inibição gabaérgica, além de ser antagonista do receptor de glutamato e inibidor fraco da anidrase carbônica. ${ }^{3,4}$

TPM é frequentemente utilizado como comedicação no tratamento da epilepsia, sendo importante a investigação de interações com outros anticonvulsivantes. Estudos mostram que o TPM tem pouco efeito sobre o metabolismo de outros fármacos, mas sua própria biotransformação pode ser fortemente induzida por outros anticonvulsivantes. ${ }^{5}$ Carbamazepina (CBZ), fenitoína (FNT) e fenobarbital (FNB) induzem o metabolismo do TPM, levando a reduções na sua concentração plasmática na ordem de 40 a $50 \%$, sugerindo que um ajuste de dose do TPM é necessário quando estes anticonvulsivantes são adicionados ou retirados do regime terapêutico. ${ }^{5}$

Diferentemente de outros anticonvulsivantes de uso mais estabelecido, uma faixa terapêutica de concentrações plasmáticas recomendada para o TPM ainda não é consensual, sendo propostas as faixas de 2 a $25 \mu \mathrm{g} \mathrm{mL} \mathrm{m}^{-1}$ por Marca et al., ${ }^{6}$ e de 5 a $25 \mu \mathrm{g} \mathrm{mL} \mathrm{m}^{-1}$ por Johannessen et al. ${ }^{7}$

Foram descritos ensaios para a determinação de TPM em plasma empregando cromatografia gasosa associada à espectrometria de massas $(\mathrm{CG}-\mathrm{EM})^{8}$ e cromatografia líquida associada à espectrometria de massas sequencial (CL-EM/EM), ${ }^{9-11}$ porém sem incluir os demais anticonvulsivantes usualmente utilizados concomitantemente. Alternativamente, diversos autores avaliaram o emprego de métodos cromatográficos associados a detectores não espectrométricos para esta aplicação. Entretanto, a determinação quantitativa do TPM é dificultada pela inexistência de cromóforos ou fluoróforos em sua molécula,

*e-mail: rafael.linden@feevale.br o que requer etapas de derivatização para a aplicação da técnica de cromatografia líquida de alta eficiência (CLAE) com detectores UV ou de fluorescência. ${ }^{1} \mathrm{O}$ TPM também pode ser determinado através de cromatografia gasosa, normalmente com o emprego de detectores seletivos para nitrogênio e fósforo (CG-DNP). ${ }^{12-14} \mathrm{~A}$ utilização dos sistemas CG-DNP para a determinação de TPM e outros fármacos é especialmente atrativa, devido à elevada sensibilidade para compostos nitrogenados e a sua relativa insensibilidade a compostos endógenos usuais. ${ }^{15}$ Também estão disponíveis no mercado internacional, mas sem registro no Brasil, ensaios para determinação de topiramato empregando imunoensaio de fluorescência polarizada (FPIA). ${ }^{16}$

Desta forma, não existe descrição na literatura de um método para determinação simultânea de TPM e dos principais anticonvulsivantes prescritos em associação, especialmente aqueles que modificam a sua farmacocinética. O objetivo do presente estudo foi desenvolver e validar um método rápido e simples para determinação simultânea de TPM, CBZ, FNT e FNB em amostras de plasma empregando cromatografia a gás com detector de nitrogênio e fósforo, com uma etapa de derivatização rápida, descrita previamente para outros anticonvulsivantes. ${ }^{14}$

\section{PARTE EXPERIMENTAL}

\section{Reagentes e amostras de referência}

O topiramato foi adquirido da United States Pharmacopeia (Rockville, EUA). Carbamazepina, fenitoína e fenobarbital foram doados pelo Laboratório Cristália (Itapira, Brasil). Todos os fármacos apresentaram teor de pureza mínimo declarado de 99,9\%. A 5-( $p$-Metilfenil)-5-fenil-hidantoína (MPPH) foi adquirida da Sigma Aldrich (St. Louis, EUA). A solução de hidróxido de trimetilfenilamônio (TMAH) 0,2 mol L ${ }^{-1}$ foi adquirida da Supelco (Bellefonte, EUA). Metanol e acetato de etila, grau HPLC, foram adquiridos da J. T. Baker (Phillipsburg, EUA). Água purificada foi obtida através de um sistema Elga Purelab Ultra da Elga Labwater (Lane End, Reino Unido). O Antiepileptic Serum Calibration Standard foi adquirido da Chromsystems (Munique, Alemanha). Tris-(hidroximetil)-aminometano foi obtido da Nuclear (Diadema, São Paulo). 


\section{Preparação das soluções e dos padrões}

Soluções-mãe individuais de TPM, CBZ, FNT e FNB foram preparadas pela dissolução dos fármacos em metanol para se obter uma concentração de $5 \mathrm{mg} \mathrm{mL}^{-1}$. A partir das soluções-mãe foram obtidas soluções metanólicas intermediárias na concentração de $1 \mathrm{mg} \mathrm{mL}^{-1}$. As soluções de trabalho combinadas foram preparadas pela diluição de alíquotas das soluções intermediárias de cada anticonvulsivante com volumes apropriados de metanol. A solução-mãe de MPPH foi preparada na concentração de $1 \mathrm{mg} \mathrm{mL}^{-1}$ em metanol e a partir desta foi obtida a solução de trabalho do padrão interno (PI) (MPPH 50 $\mu \mathrm{g} \mathrm{mL}^{-1}$ ) através de nova diluição com metanol. A solução derivatizante de TMAH $0,07 \mathrm{~mol} \mathrm{~L}^{-1}$ foi preparada pela diluição da solução TMAH 0,2 mol L-1 com metanol. O tampão Tris $\mathrm{pH}$ 9,0 foi obtido pela dissolução de 24,3 g de tris-(hidroximetil)-amino-metano em 1 $\mathrm{L}$ de água purificada, sendo o $\mathrm{pH}$ ajustado com $\mathrm{NaOH} 0,1 \mathrm{~mol} \mathrm{~L}^{-1}$.

\section{Equipamento e condições cromatográficas}

As análises foram realizadas em um cromatógrafo a gás Varian CP-3800, com detetor de nitrogênio e fósforo e autoamostrador VarianPal, controlados pelo programa Galaxie Workstation, todos provenientes da Varian (Midlesburg, Holanda). A separação foi realizada em uma coluna DB-1 (Agilent Technologies, EUA), com $30 \mathrm{~m}$ de comprimento, $0,32 \mathrm{~mm}$ de d.i. e espessura do revestimento interno de $1,0 \mu \mathrm{m}$. A temperatura do injetor foi de $270{ }^{\circ} \mathrm{C}$. As amostras foram injetadas na condição sem divisão de fluxo. $\mathrm{O}$ gás de arraste utilizado foi hélio (White Martins), em fluxo constante de 3,0 mL $\mathrm{min}^{-1}$. O detector foi mantido a $310^{\circ} \mathrm{C}$, com corrente de $3,0 \mathrm{pA}$. O programa de temperatura do forno foi o seguinte: temperatura inicial de $170{ }^{\circ} \mathrm{C}$ por $2 \mathrm{~min}$ com uma rampa de $10{ }^{\circ} \mathrm{C} / \mathrm{min}$ até temperatura final de $270^{\circ} \mathrm{C}$, mantendo-se esta temperatura por $0,5 \mathrm{~min}$. A duração da análise cromatográfica foi de $12,5 \mathrm{~min}$.

\section{Preparação das amostras}

Amostras de $100 \mu \mathrm{L}$ de plasma foram transferidas para microtubos de polipropileno e acrescentados $50 \mu \mathrm{L}$ da solução de trabalho do padrão interno, $150 \mu \mathrm{L}$ de tampão Tris $\mathrm{pH}$ 9,0 e, em seguida, $1 \mathrm{~mL}$ de acetato de etila. A mistura foi homogeneizada em vórtex por $30 \mathrm{~s}$ e posteriormente foi centrifugada a $12.000 \mathrm{~g}$ por $10 \mathrm{~min}$. Do sobrenadante, $850 \mu \mathrm{L}$ da fase orgânica foram transferidos para um novo microtubo de polipropileno e evaporados até a secura a $50{ }^{\circ} \mathrm{C}$, sob fluxo de ar. O extrato seco foi retomado com $100 \mu \mathrm{L}$ da solução derivatizante TMAH $0,07 \mathrm{M}$ e transferido para um frasco do autoamostrador. Uma alíquota de $1 \mu \mathrm{L}$ desta mistura foi injetada no cromatógrafo a gás.

\section{Seletividade}

Foram processadas amostras de plasma de 6 indivíduos não usuários dos fármacos avaliados neste estudo e a presença de picos interferentes nos tempos de retenção dos analitos foi avaliada.

\section{Estabilidade}

Foram preparadas amostras de plasma controle para estudo de estabilidade em concentração baixa (CQEB) e concentração alta (CQEA), as quais foram preparadas conforme descrito anteriormente e mantidas no autoamostrador do cromatógrafo com injeções em intervalos de $1 \mathrm{~h}$ durante um período de $11 \mathrm{~h}$. O CQEB conteve TPM, CBZ, FNT e FNB nas concentrações de 2,50; 2,00; 2,50 e 5,00 $\mu \mathrm{g}$ $\mathrm{mL}^{-1}$, respectivamente. O CQEA conteve TPM, CBZ, FNT e FNB nas concentrações de 25,$00 ; 20,00 ; 25,00$ e $50,00 \mu \mathrm{g} \mathrm{mL}^{-1}$, respectivamente. A estabilidade de bancada foi avaliada através da diferença percentual entre o valor das áreas dos analitos obtidas no tempo inicial e as obtidas nos demais tempos, sendo considerada aceitável se todos os valores encontrados estivessem na faixa de 90 a $110 \%$ da razão das áreas entre os analitos e o PI obtida no tempo inicial.

A estabilidade em ciclos de congelamento e descongelamento foi avaliada em amostras de controle de qualidade em nível baixo (CQB), médio (CQM) e alto (CQA), descritas nos ensaios de precisão e exatidão, as quais foram analisadas em triplicata no dia da preparação e novamente analisadas em triplicata após um ciclo de congelamento e descongelamento. A estabilidade em ciclos de congelamento e descongelamento foi avaliada pela diferença percentual entre a média das concentrações obtidas no dia de preparação das amostras controle e as médias obtidas no ciclo. A estabilidade em ciclos de congelamento e descongelamento foi considerada aceitável se todos os valores encontrados estivessem na faixa de 90 a $110 \%$ das concentrações obtidas no início da série.

\section{Linearidade}

A linearidade dos modelos de calibração foi avaliada em 6 níveis, em sextuplicata para cada nível. Soluções de trabalho combinadas dos analitos foram adicionadas em amostras de plasma isento de fármacos, a fim de se obter soluções analíticas nas concentrações 1,$00 ; 2,50 ; 5,00 ; 10,00 ; 25,00$ e $50,00 \mu \mathrm{g} \mathrm{mL}^{-1}$ para TPM e FNT; 1,$00 ; 2,00 ; 4,00 ; 8,00 ; 20,00$ e 40,00 $\mu \mathrm{g} \mathrm{mL}^{-1}$ para a CBZ e 1,00; 5,00; 10,$00 ; 20,00 ; 50,00$ e $100,00 \mu \mathrm{g} \mathrm{mL}^{-1}$ para o FNB. As curvas analíticas foram construídas calculando-se as razões entre as áreas dos picos de cada analito e do padrão interno e comparando-se estas razões com as concentrações nominais dos calibradores. A homocedasticidade dos dados de calibração foi avaliada com o teste F com nível de confiança de $95 \%$. As curvas foram ajustadas através de regressão linear empregando-se diversos fatores ponderais $\left(1 / \mathrm{x}, 1 / \mathrm{x}^{0,5}, 1 / \mathrm{x}^{2}, 1 / \mathrm{y}, 1 / \mathrm{y}^{0,5}\right.$, $\left.1 / \mathrm{y}^{2}\right)$. Os modelos de calibração foram avaliados pelos coeficientes de correlação (r) e pelo erro percentual cumulativo ( $\sum \%$ ER), de acordo com Almeida et al.. ${ }^{17}$ Curvas analíticas diárias, usando as mesmas concentrações (medidas únicas por concentração), foram preparadas durante o processamento de todos os lotes analíticos.

\section{Ensaios de precisão e exatidão}

Foram preparadas amostras de plasma controle para avaliação da precisão e da exatidão em concentração baixa (CQB), média (CQM) e alta (CQA). O CQB conteve TPM, CBZ, FNT e FNB nas concentrações de 2,00; 1,50; 2,00 e 4,00 $\mu \mathrm{g} \mathrm{mL}{ }^{-1}$, respectivamente. $\mathrm{O}$ CQM conteve TPM, CBZ, FNT e FNB nas concentrações de 20,00; 15,00; 20,00 e 40,00 $\mu \mathrm{g} \mathrm{mL} \mathrm{m}^{-1}$, respectivamente. O CQA conteve TPM, CBZ, FNT e FNB nas concentrações de 40,00; 30,00; 40,00 e $80,00 \mu \mathrm{g} \mathrm{mL} \mathrm{m}^{-1}$, respectivamente. As análises foram realizadas como mencionado acima em triplicata e repetidas em 5 dias diferentes. A precisão intraensaios e a precisão interensaios foram calculadas pela análise de variância (ANOVA), usando-se "dia" como variável agrupadora. A exatidão foi calculada como percentagem média obtida do valor teórico adicionado nas amostras. O critério de aceitação para exatidão foi valores médios de $\pm 15 \%$ do valor nominal e para precisão foi um CV máximo de $15 \%{ }^{18}$

\section{Limite de quantificação}

Uma amostra de controle de qualidade no nível do limite de quantificação, na concentração de $1,00 \mu \mathrm{g} \mathrm{mL}^{-1}$ (CQLQ), foi testada em triplicata em 3 dias diferentes e sua precisão e exatidão foram 
calculadas conforme descrito anteriormente. Os critérios de aceitação para o CQLQ foram precisão (CV\%) $\leq 20$ e exatidão entre 80 a 120\%, de acordo com Shah et al..18

\section{Aplicação do método}

O método desenvolvido foi aplicado a 22 amostras de plasma obtidas de pacientes de um serviço de neurologia de um hospital geral, colhidas entre setembro e outubro de 2010. As amostras foram coletadas por punção venosa para tubos contendo EDTA como anticoagulante. As coletas foram realizadas $30 \mathrm{~min}$ antes da próxima dose dos medicamentos. Após a coleta, os tubos foram centrifugados por 10 min e o plasma foi separado e mantido a $-20^{\circ} \mathrm{C}$ até a análise. $\mathrm{O}$ estudo foi aprovado pelo Comitê de Ética da Irmandade Santa Casa de Misericórdia de Porto Alegre.

\section{RESULTADOS E DISCUSSÃO}

\section{Cromatografia e preparação da amostra}

A utilização da cromatografia gasosa associada ao detector de nitrogênio e fósforo mostrou-se apropriada para a determinação simultânea e quantitativa dos analitos avaliados. A análise cromatográfica teve duração total de 12,5 min, com tempos de retenção de 6,$55 ; 7,65 ; 8,85 ; 9,74$ e 10,66 min para FNB, CBZ, TPM, FNT e PI, respectivamente (Figura 1 ).

Interferentes endógenos não foram identificados nos tempos de retenção dos analitos. Dois picos de origem endógena foram identificados, com eluição nos tempos de 7,12 e 8,13 min, não apresentando interferência com nenhum dos analitos. A técnica utilizada para o preparo da amostra foi relativamente simples, com o emprego de apenas $100 \mu \mathrm{L}$ de plasma e de um pequeno volume de solvente orgânico. Devido à sensibilidade do detector DNP, o volume de amostra foi significativamente inferior ao empregado em estudo anterior, no qual se determinou TPM por CG-EM no modo de monitoramento de íons, com utilização de $500 \mu \mathrm{L}$ de plasma. ${ }^{8}$

O uso do derivatizante TMAH permitiu a obtenção de derivados metilados, formados durante a injeção no cromatógrafo (Figura 2), os quais apresentaram comportamento cromatográfico adequado, com picos de simetria significativamente melhorada em comparação com seus análogos não derivatizados, que apresentaram tempos de retenção superiores $(8,35 ; 9,50 ; 10,72 ; 11,62$ e 12,75 min para FNB, CBZ, TPM, FNT e PI, respectivamente). Cabe destacar que existem relatos da utilização desta reação para a determinação de barbitúricos e de TPM isoladamente, ${ }^{14}$ mas este é o primeiro relato do emprego desta estratégia para a determinação simultânea de TPM, CBZ, FNT e FNB. A estratégia de preparo de amostra empregada foi mais simples que a utilizada em estudos anteriores de determinação de TPM por cromatografia a gás, os quais empregaram extração em fase sólida previamente à análise por CG-EM e extração líquido-líquido com etapas de reextração previamente à análise por CG-DNP ${ }^{12}$ e CG-DIC. ${ }^{13}$

\section{Validação do método}

Não houve indicação de instabilidade dos analitos em quaisquer das condições testadas. As amostras foram estáveis quando submetidas ao teste de estabilidade de bancada, com variações entre 1,3 e $8,2 \%$, permitindo o processamento de grandes lotes analíticos sem conservação especial dos extratos. A avaliação da estabilidade em ciclos de congelamento e descongelamento determinou variações, ao final do $3^{\circ}$ ciclo, de $-0,7$ a 5,5\% para os diferentes analitos, as quais atenderam os critérios de aceitação.

Os dados das curvas analíticas apresentaram heteroscedasticidade
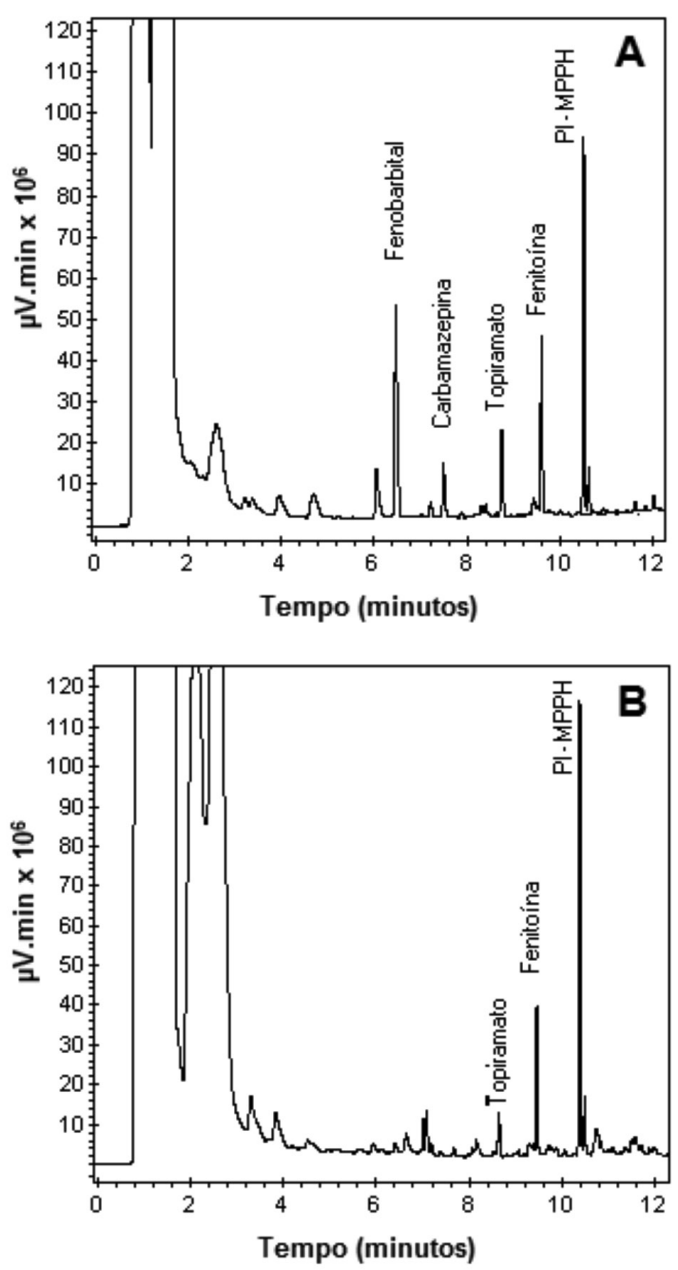

Figura 1. Separação cromatográfica: (A) solução analítica preparada em plasma contendo $10 \mu \mathrm{g} \mathrm{mL}^{-1}$ de topiramato e fenitoína, $8 \mu \mathrm{g} \mathrm{mL}^{-1}$ de carbamazepina e $20 \mu \mathrm{g} \mathrm{mL}^{-1}$ de fenobarbital; (B) amostra clínica de plasma contendo $1,12 \mu \mathrm{g} \mathrm{mL}^{-1}$ de topiramato e 5,89 $\mu \mathrm{g} \mathrm{mL}^{-1}$ de fenitoína

significativa, com $F_{\text {exp }}=280$ a $18596\left(F_{\text {tab }(5 ; 5 ; 0,95)}=5,05\right)$ para os diferentes analitos. Desta forma, foram avaliados diversos fatores ponderais para a obtenção do modelo de regressão. Dentre os modelos avaliados, a regressão utilizando o fator ponderal $1 / \mathrm{x}^{2}$ apresentou a menor $\sum \%$ ER, com valores entre $3,7^{-14}$ a $1,5^{-13}$, bem como coeficientes de correlação entre 0,9977 a 0,9991 , sendo selecionada para os demais estudos de validação.

Os resultados dos ensaios de precisão e exatidão mostraram-se adequados, conforme Tabela 1. A precisão intraensaios apresentou valores entre 2,5 e 7,3\% e a precisão interensaios entre 1,6 e 5,20\%, demonstrando a adequada repetibilidade do método. A exatidão foi determinada entre 100,1 a 104,2\%, também dentro dos critérios de aceitação para métodos bioanalíticos preconizados por Shah et al.. ${ }^{13}$ Os limites de quantificação obtidos são significativamente inferiores ao menor nível terapêutico de cada fármaco, ao se considerar o propósito do método deste estudo, o qual é focado no monitoramento terapêutico de pacientes usuários de um ou mais destes anticonvulsivantes. O limite de quantificação para todos os analitos foi de 1,00 $\mu \mathrm{g} \mathrm{mL} \mathrm{L}^{-1}$, concentração na qual foi possível obter precisão (entre 5,85 a 9,38\%) e exatidão (102,6 a 106,3\%) aceitáveis.

\section{Aplicação do método}

O método desenvolvido foi aplicado a 22 amostras de plasma 
A<smiles>CN(C)C(=O)N1c2ccccc2C=Cc2ccccc21</smiles>

B<smiles>CN1C(=O)N(C)C(c2ccccc2)(c2ccccc2)C1(O)c1ccccc1</smiles>

c<smiles>CCC1(c2ccccc2)C(=O)NC(=O)NC1=O</smiles>

Fenobarbital

D<smiles>CC1(C)O[C@H]2CO[C@@](O)(COS(N)(=O)=O)[C@H]3OC(C)(C)O[C@H]3[C@H]2O1</smiles>

E<smiles>Cc1ccc(C2(c3ccccc3)NC(=O)NC2=O)cc1</smiles>

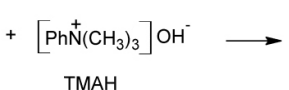<smiles>Cc1ccc(C2(c3ccccc3)C(=O)N(C)C(=O)N2C)cc1</smiles>

Figura 2. Reações de metilação com hidróxido de trimetilfenil amônio (TMAH): (A) metilação da carbamazepina; (B) metilação da fenitoína; (C) metilação do fenobarbital; (D) metilação do topiramato; (E) metilação do MPPH.Ph = fenil

coletadas em condições de vale. A média das concentrações de TPM foi de $3,22 \mu \mathrm{g} \mathrm{mL}^{-1}$ (faixa de 0,82 a $6,33 \mu \mathrm{g} \mathrm{mL}^{-1}$ ), sendo que 5 amostras $(23 \%)$ apresentaram concentrações inferiores ao limite inferior da faixa terapêutica, ${ }^{6}$ o que corrobora a utilização do monitoramento terapêutico em pacientes em farmacoterapia com topiramato. Dentre os pacientes avaliados, a associação mais comum foi com ácido valproico $(n=18)$. A associação com CBZ, FNT e FNB ocorreu em 6 pacientes, com duas ocorrências para cada fármaco. Os resultados encontrados são apresentados na Tabela 2. Dos 5 pacientes em provável subdose, 3 utilizavam topiramato em associações com fármacos indutores do metabolismo hepático. A média das concentrações de TPM em monoterapia foi de $3,50 \mu \mathrm{g} \mathrm{mL} \mathrm{m}^{-1}$, sendo que a média das concentrações de TPM em politerapia foi de $2,53 \mu \mathrm{g} \mathrm{mL} \mathrm{m}^{-1}$.

\section{CONCLUSÃO}

Foi desenvolvido e validado um método para a determinação simultânea de topiramato, fenitoína, carbamazepina e fenobarbital em plasma por CG-DNP. A preparação das amostras foi simples e rápida e baseou-se em extração líquido-líquido e metilação no injetor do cromatógrafo com TMAH, sendo a primeira descrição desta estratégia

Tabela 1. Valores determinados para precisão e exatidão do método na avaliação de quatro níveis de concentração

\begin{tabular}{|c|c|c|c|c|c|}
\hline \multirow{2}{*}{$\begin{array}{l}\text { Fármaco } \\
\text { (C.V.\%) }\end{array}$} & \multirow{2}{*}{$\begin{array}{l}\text { Amostra } \\
\text { controle }\end{array}$} & \multirow{2}{*}{$\begin{array}{l}\text { Concen- } \\
\text { tração } \\
\left(\mu \mathrm{gLL}^{-1}\right)\end{array}$} & \multicolumn{2}{|c|}{ Precisão } & \multirow{2}{*}{$\begin{array}{c}\text { Exatidão } \\
(\%)\end{array}$} \\
\hline & & & $\begin{array}{c}\text { Intraensaios } \\
\text { (C.V.\%) }\end{array}$ & $\begin{array}{c}\text { Interensaios } \\
\text { (C.V.\%) }\end{array}$ & \\
\hline \multirow[t]{4}{*}{ Topiramato } & CQLQ & 1,00 & 5,9 & 6,3 & 105,3 \\
\hline & CQB & 2,00 & 3,6 & 2,1 & 103,5 \\
\hline & CQM & 20,00 & 2,9 & 5,2 & 103,9 \\
\hline & CQA & 40,00 & 4,0 & 3,6 & 104,1 \\
\hline \multirow[t]{4}{*}{ Fenitoína } & CQLQ & 1,00 & 6,4 & 7,0 & 106,3 \\
\hline & CQB & 2,00 & 4,3 & 2,3 & 104,2 \\
\hline & CQM & 20,00 & 2,6 & 3,5 & 101,9 \\
\hline & CQA & 40,00 & 2,5 & 2,9 & 101,3 \\
\hline \multirow{4}{*}{$\begin{array}{l}\text { Carbamaze- } \\
\text { pina }\end{array}$} & CQLQ & 1,00 & 8,4 & 9,4 & 102,6 \\
\hline & CQB & 1,50 & 7,3 & 4,6 & 101,2 \\
\hline & CQM & 15,00 & 4,1 & 2,8 & 100,1 \\
\hline & CQA & 30,00 & 3,5 & 2,2 & 100,7 \\
\hline \multirow[t]{4}{*}{ Fenobarbital } & CQLQ & 1,00 & 6,1 & 5,9 & 103,3 \\
\hline & CQB & 4,00 & 4,1 & 2,2 & 101,2 \\
\hline & CQM & 40,00 & 3,3 & 2,4 & 101,8 \\
\hline & CQA & 80,00 & 2,9 & 1,6 & 101,3 \\
\hline
\end{tabular}

CQLQ: controle de qualidade no limite de quantificação; CQB: controle de qualidade baixo; CQM: controle de qualidade médio; CQA: controle de qualidade alto. $\mathrm{n}=15$ para CQB, CQM e CQA, $n=9$ para CQLQ.

Tabela 2. Concentrações de topiramato, carbamazepina, fenitoína e fenobarbital determinadas em amostras clínicas

\begin{tabular}{|c|c|c|c|c|}
\hline \multirow{2}{*}{ Paciente } & \multicolumn{4}{|c|}{ Concentração $\left(\mu \mathrm{g} \mathrm{mL}^{-1}\right)$} \\
\hline & Topiramato & Carbamazepina & Fenitoína & Fenobarbital \\
\hline 1 & 0,82 & - & 13,35 & - \\
\hline 2 & 3,16 & - & - & 4,01 \\
\hline 3 & 4,86 & - & - & 14,0 \\
\hline 4 & 1,41 & 5,67 & - & - \\
\hline 5 & 1,12 & - & 5,89 & - \\
\hline 6 & 3,80 & 1,11 & - & - \\
\hline 7 & 3,02 & - & - & - \\
\hline 8 & 3,38 & - & - & - \\
\hline 9 & 3,11 & - & - & - \\
\hline 10 & 6,33 & - & - & - \\
\hline 11 & 5,12 & - & - & - \\
\hline 12 & 4,46 & - & - & - \\
\hline 13 & 4,30 & - & - & - \\
\hline 14 & 1,28 & - & - & - \\
\hline 15 & 6,07 & - & - & - \\
\hline 16 & 2,51 & - & - & - \\
\hline 17 & 4,20 & - & - & - \\
\hline 18 & 2,46 & - & - & - \\
\hline 19 & 1,78 & - & - & - \\
\hline 20 & 2,00 & - & - & - \\
\hline 21 & 2,00 & - & - & - \\
\hline 22 & 3,57 & - & - & - \\
\hline
\end{tabular}


para a quantificação simultânea destes analitos. O método mostrou-se adequado para aplicação clínica, sendo aplicado a 22 pacientes sob terapia com topiramato e fármacos associados. Os parâmetros de precisão, exatidão e sensibilidade são adequados para o monitoramento terapêutico dos fármacos, permitindo a determinação fidedigna destes fármacos em laboratórios que disponham de equipamentos de CG com detector de nitrogênio e fósforo.

\section{REFERENCIAS}

1. Contin, M.; Riva, R.; Albani, F.; Avoni, P.; Baruzzi, A.; Ther. Drug Monit.2002, 24, 332.

2. Matar, K. M.; Clin. Chim. Acta 2010, 411, 729.

3. Rocha, G. P.; Batista, B. H.; Nunes, M. L.; J. Pediatr. 2004, 80, 45.

4. Neels, H. M.; Sierens, A. C.; Naelaerts, K.; Scharpé, S. L.; Hatfield, G. M.; Lambert, W. E.; Clin. Chem. Lab. Med. 2004, 42, 1228.

5. May, T. W.; Rambeck, B.; Jürgens, U.; Ther. Drug Monit. 2002, 24, 366.

6. La Marca, G.; Malvagia, S.; Filippi, L.; Fiorini, P.; Innocenti, M.; Luceri, F.; Pieraccini, G.; Moneti, G.; Francese, S.; Dani, F. R.; Guerrini, R.; J. Pharm. Biomed. Anal. 2008, 48, 1392.

7. Johannessen, S. I.; Battino, D.; Berry, D. J.; Bialer, M.; Krämer, G.; Tomson, T.; Patsalos, P. N.; Ther. Drug Monit. 2003, 25, 347.

8. Conway, J. M.; Birnbaum, A. K.; Marino, S. E.; Cloyd, J. C. C.; Remmel, R. P.; Biomed. Chromatogr. 2012, 26, 1071.
9. Christensen, J.; Hojskov, C. S.; Poulsen, J. H.; Ther. Drug Monit. 2002, 24, 658 .

10. Park, J. H.; Lee, M. H.; Rhim, S. Y.; Song, J. C.; Kim, J. M.; Shaw, L. M.; Kang. J. S.; Biomed. Chromatogr. 2008, 22, 822.

11. Britzi, M.; Soback, S.; Isoherranen, N.; Levy, R. H.; Perucca, E.; Doose, D. R.; Maryanoff, B. E.; Bialer, M.; Ther. Drug Monit. 2003, 25, 314.

12. Riffitts, J. M.; Gisclon, L. G.; Stubbs, R. J. ; Palmer, M. E.; J. Pharm. Biomed. Anal. 1999, 19, 363.

13. Tang, P. H.; Miles, M. V.; Glauser, T. A.; Coletta, L.; Doughman, N.; Doose, D.; Frey, M.; DeGrauw, A.; Ther. Drug Monit. 2000, 22, 195.

14. Malakova, J.; Brozmanova, V.; Vorisek, V.; Prochazkova, V.; Palicka, V.; Chromatographia 2007, 66, 363.

15. Lizot, L. F.; Silva, L. L.; Spaniol, B.; Antunes, M. V.; Linden, R.; Lanaro, R.; Quim. Nova 2012, 35, 1222.

16. Miles, M. V.; Tang, P. H.; Glauser, T. A.; Ryan, M. A.; Grim, S. A.; Strawsburg, R. H.; De Grauw, T. J.; Baumann, R. J.; Pediatr. Neurol. 2003, 29, 143.

17. Almeida, A. M.; Castel-Branco, M. M.; Falcão, A. C.; J. Chromatogr. B: Anal. Technol. Biomed. Life Sci. 2002, 774, 215.

18. Shah, V. P.; Midha, K. K.; Findlay, J. W. A.; Hill, H. M.; Hulse, J. D.; McGilveray, I. J.; McKay, G.; Miller, K. J.; Patnaik, R. N.; Powell, M. L.; Tonelli, A.; Viswanathan, C. T.; Yacobi, A.; Pharm. Res. 2000, 17, 1551 